\title{
Single LAYER Monopole HeXagonal MICROSTRIP PATCH ANTENNA FOR SATELLITE TELEVISION
}

\author{
Supriya Jana ${ }^{1}$, Bipadtaran Sinhamahapatra ${ }^{2}$, Sudeshna Dey ${ }^{3}$, \\ Arnab Das ${ }^{4}$, Bipa Datta $^{5}$, Moumita Mukherjee ${ }^{6}$, Samiran Chatterjee $^{7}$ \\ 1,2,3,4,5 Department of ECE, West Bengal University of Technology, Brainware \\ Group of Institutions, Barasat, West Bengal, India. \\ ${ }^{1}$ supriyajana9734@yahoo.co. in, ${ }^{2}$ taranbipad06 @gmail.com, ${ }^{3}$ sudesna.ece \\ egmail.com, \\ ${ }^{4}$ u_call_arnabeyahoo.co.in, ${ }^{5}$ bipa.datta@gmail.com
}

${ }^{6}$ Centre for Millimeter wave Semiconductor Devices and Systems, University of Calcutta, West Bengal, India

mm_drdo@yahoo.com

${ }^{7}$ University of Kalyani, Kalyani, West Bengal, India.

samiranengineer@gmail.com

\section{ABSTRACT}

A single layer monopole hexagonal patch antenna is thoroughly simulated in this paper. Resonant frequency has been reduced drastically by cutting three unequal slots which are the combinations of one circle and two irregular rectangular slots from the conventional microstrip patch antenna. It is shown that the simulated results are in acceptable agreement. More importantly, it is also shown that the differentially-driven microstrip antenna has higher gain of simulated $3.36 \mathrm{dBi}$ at $9.61 \mathrm{GHz}$ and $-0.43 \mathrm{dBi}$ at $13.57 \mathrm{GHz}$ and beam width of simulated $162.08^{0}$ at $9.61 \mathrm{GHz}$ and $53.45^{\circ}$ at $13.57 \mathrm{GHz}$ of the single-ended microstrip antenna. Compared to a conventional microstrip patch antenna, simulated antenna size has been reduced by $50.80 \%$ with an increased frequency ratio.

\section{KEYWORDS}

Compact, Patch, Slot, Resonant frequency, Bandwidth.

\section{INTRODUCTION}

In recent years, demand for small antennas on wireless communication has increased the interest of research work on compact microstrip antenna design among microwave and wireless engineers [1-6]. Because of their simplicity and compatibility with printed-circuit technology microstrip antennas are widely used in the microwave frequency spectrum. Simply a microstrip antenna is a rectangular or other shape, patch of metal on top of a grounded dielectric substrate. Microstrip patch antennas are attractive in antenna applications for many reasons. They are easy and cheap to manufacture, lightweight, and planar to list just a few advantages. Also they can be manufactured either as a stand-alone element or as part of an array. However, these advantages 
are offset by low efficiency and limited bandwidth. In recent years much research and testing has been done to increase both the bandwidth and radiation efficiency of microstrip antennas.

Due to the recent interest in broadband antennas a microstrip patch antenna was developed to meet the need for a cheap, low profile, broadband antenna. This antenna could be used in a wide range of applications such as in the communications industry for cell phones or satellite communication. Our aim is to reduce the size of the antenna as well as increase the operating bandwidth. The proposed antenna (substrate with $\varepsilon_{r}=4.4$ ) has a gain of $3.19 \mathrm{dBi}$ and presents a size reduction of $54.55 \%$ when compared to a conventional microstrip patch $(10 \mathrm{~mm} \mathrm{X} 6 \mathrm{~mm})$. The simulation has been carried out by IE3D [14] software which uses the MoM method. Due to the small size, low cost and low weight this antenna is a good entrant for the application of XBand [7-10]microwave communication and Ku-Band RADAR communication \& satellite communication.

The $\mathrm{X}$ band and $\mathrm{Ku}$-Band defined by an IEEE standard for radio waves and radar engineering with frequencies that ranges from 8.0 to $12.0 \mathrm{GHz}$ and 12.0 to $18.0 \mathrm{GHz}$ respectively. The $\mathrm{X}$ band is used for short range tracking, missile guidance, marine, radar and air bone intercept. Especially it is used for radar communication ranges roughly from $8.29 \mathrm{GHz}$ to $11.4 \mathrm{GHz}$. The $\mathrm{Ku}$ band is used for high resolution mapping and satellite altimetry. Especially, Ku Band is used for tracking the satellite within the ranges roughly from $12.87 \mathrm{GHz}$ to $14.43 \mathrm{GHz}$. In this paper the micro strip patch antenna is designed for use in a satellite TV at $13.5773 \mathrm{GHz}$. The results obtained provide a workable antenna design for incorporation in a satellite TV. Recently the Direct broadcast satellite (DBS) system uses the upper portion of the Ku band.

\section{Antenna Design}

The configuration of the conventional printed antenna is shown in Figure 1 with $\mathrm{L}=6 \mathrm{~mm}, \mathrm{~W}=10$ $\mathrm{mm}$, substrate (PTFE) thickness $\mathrm{h}=1.6 \mathrm{~mm}$, dielectric constant $\varepsilon_{\mathrm{r}}=4.4$. Coaxial probe-feed (radius $=0.5 \mathrm{~mm}$ ) is located at $\mathrm{W} / 2$ and $\mathrm{L} / 3$. Assuming practical patch width $\mathrm{W}=10 \mathrm{~mm}$ for efficient radiation and using the equation [6],

$$
\mathrm{f}_{\mathrm{r}}=\frac{\mathrm{c}}{2 \mathrm{~W}} \times \sqrt{\frac{2}{\left(1+\varepsilon_{\mathrm{r}}\right)}}
$$

Where, $\mathrm{c}=$ velocity of light in free space. Using the following equation [9] we determined the practical length $\mathrm{L}(=6 \mathrm{~mm})$.

$L=\mathrm{L}_{\mathrm{eff}}-2 \Delta \mathrm{L}$

Where, $\frac{\Delta L}{h}=\left[0.412 \times \frac{\left(\varepsilon_{\text {reff }}+0.3\right) \times(\mathrm{W} / \mathrm{h}+0.264)}{\left(\varepsilon_{\text {reff }}-0.258\right) \times(\mathrm{W} / \mathrm{h}+0.8)}\right]$

$\varepsilon_{\text {reff }}=\left[\left(\frac{\varepsilon_{\mathrm{r}}+1}{2}\right)+\frac{\varepsilon_{\mathrm{r}}-1}{\left(2 \times \sqrt{\left(1+12 \times \frac{h}{W}\right)}\right)}\right]$

and $\quad L_{e f f}=\left[\frac{c}{2 \times f_{r} \times \sqrt{\epsilon_{e f f}}}\right]$

Where, $\mathrm{L}_{\text {eff }}=$ Effective length of the patch, $\Delta \mathrm{L} / \mathrm{h}=$ Normalized extension of the patch length, $\varepsilon_{\text {reff }}$ $=$ Effective dielectric constant. 


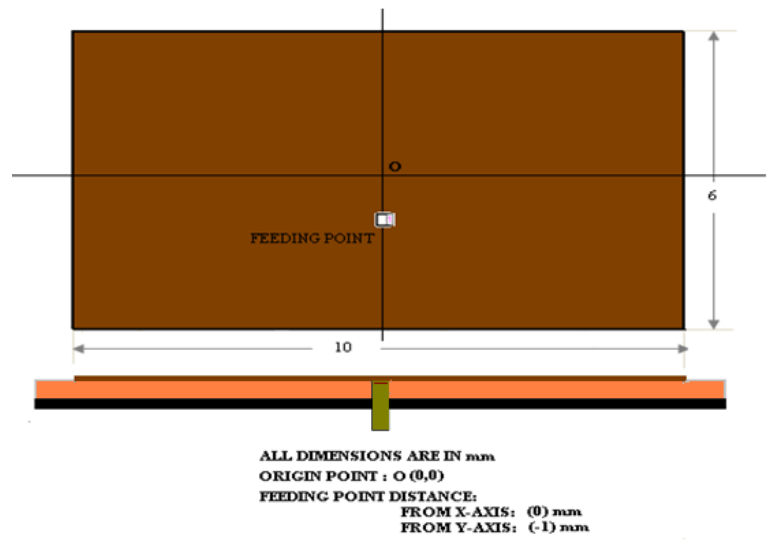

Figure 1: Conventional Antenna configuration

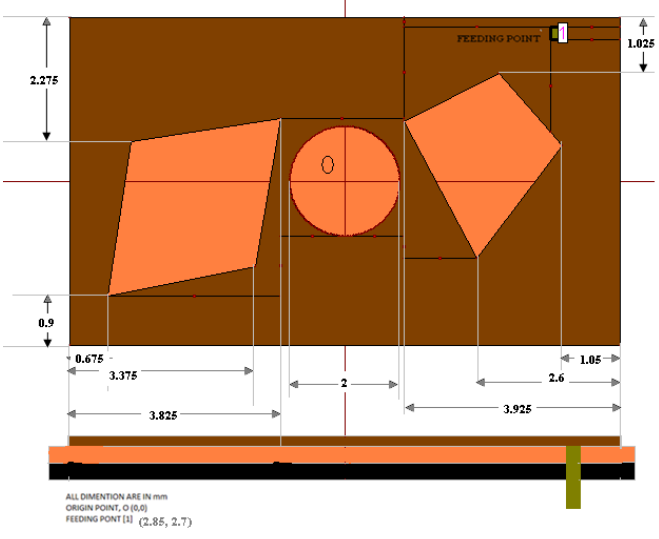

Figure 2: Simulated Antenna configuration

Figure 2 shows the configuration of simulated printed antenna designed with similar PTFE substrate. Two equal slots which are the combinations of two triangular and a rectangular slot at the upper right and lower left corner and the location of coaxial probe-feed (radius $=0.5 \mathrm{~mm}$ ) are shown in the figure 2 .

\section{RESUlTS AND DisCUSSION}

Simulated (using IE3D [10]) results of return loss in conventional and simulated antenna structures are shown in Figure 3-4. A significant improvement of frequency reduction is achieved in simulated antenna with respect to the conventional antenna structure.

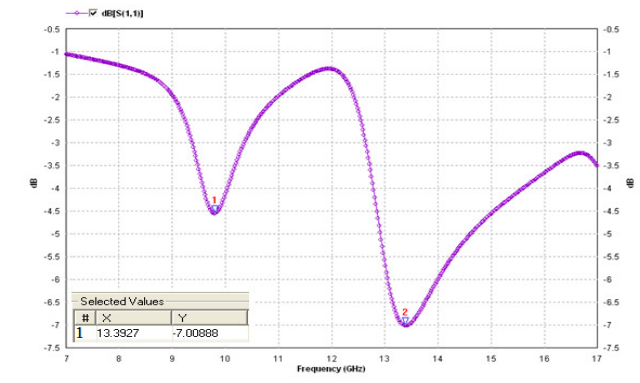

Figure 3: Return Loss vs. Frequency (Conventional Antenna)

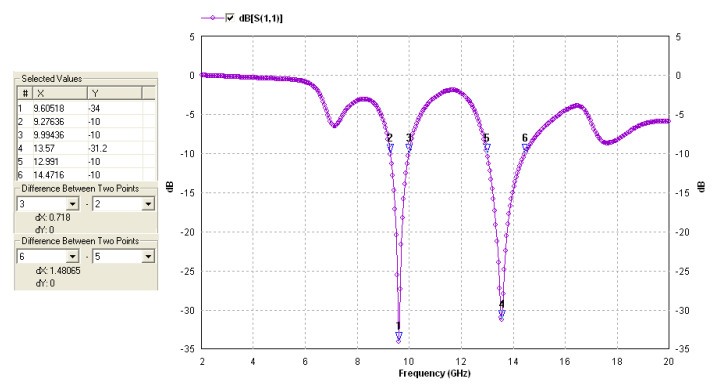

Figure 4: Return Loss vs. Frequency (Slotted Antenna)

In the conventional antenna return loss of about $-7.01 \mathrm{~dB}$ is obtained at $13.39 \mathrm{GHz}$. Comparing fig. 3 and fig. 4 it may be observed that for the conventional antenna (fig.3), there is practically no resonant frequency at around $9.61 \mathrm{GHz}$ with a return loss of around $-6 \mathrm{~dB}$. For the simulated antenna there is a resonant frequency at around $9.61 \mathrm{GHz}$ where the return loss is as high as -34 $\mathrm{dB}$.

Due to the presence of slots in simulated antenna resonant frequency operation is obtained with large values of frequency ratio. The first and second resonant frequency is obtained at $f_{1}=9.61$ $\mathrm{GHz}$ with return loss of about $-34 \mathrm{~dB}$ and at $\mathrm{f}_{2}=13.57 \mathrm{GHz}$ with return losses $-31.2 \mathrm{~dB}$ respectively. 
Corresponding $10 \mathrm{~dB}$ band width obtained for Antenna 2 at f1, f2 are $718 \mathrm{MHz}$ and $1.48 \mathrm{GHz}$ respectively. The simulated E plane and H-plane radiation patterns are shown in Figure 5-12. The simulated E plane radiation pattern of simulated antenna for $9.61 \mathrm{GHz}$ is shown in figure 5 .

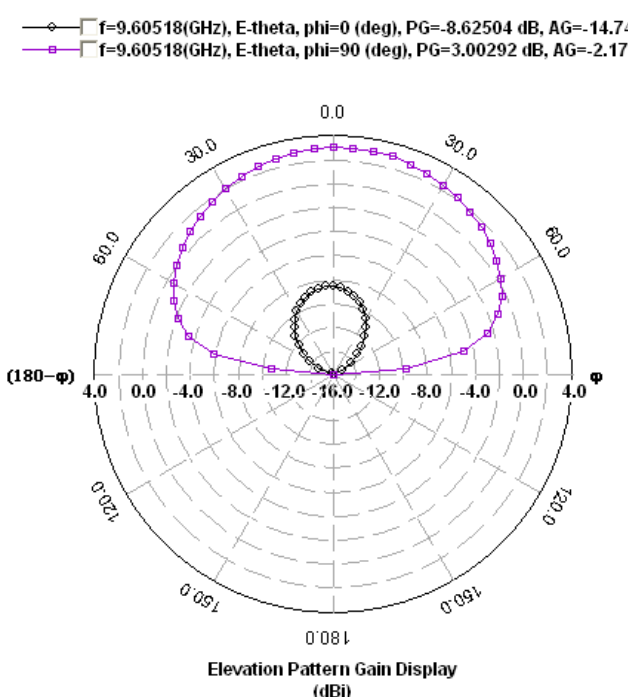

Figure 5: E-Plane Radiation Pattern for Slotted Antenna at $9.61 \mathrm{GHz}$
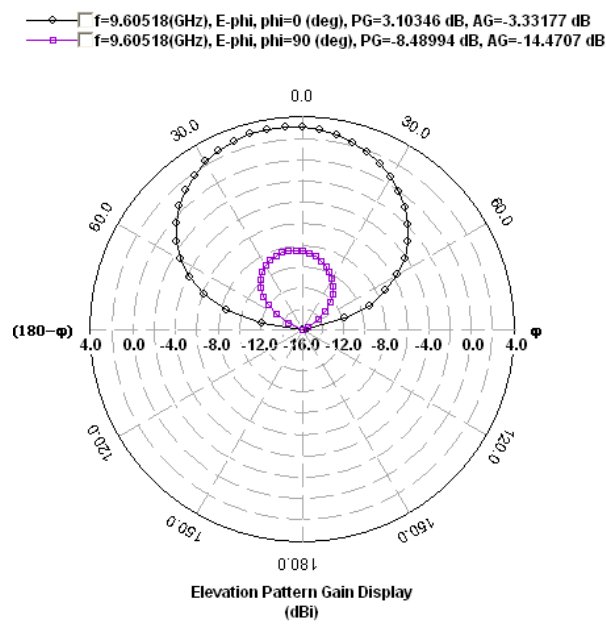

Figure 6: H-Plane Radiation Pattern for slotted Antenna at $9.61 \mathrm{GHz}$

The simulated $\mathrm{H}$ plane radiation pattern of simulated antenna for $9.61 \mathrm{GHz}$ is shown in figure 6 . The simulated E -plane \& H-plane radiation pattern (3D) of simulated antenna for $9.61 \mathrm{GHz}$ is shown in figure $7 \&$ figure 8.

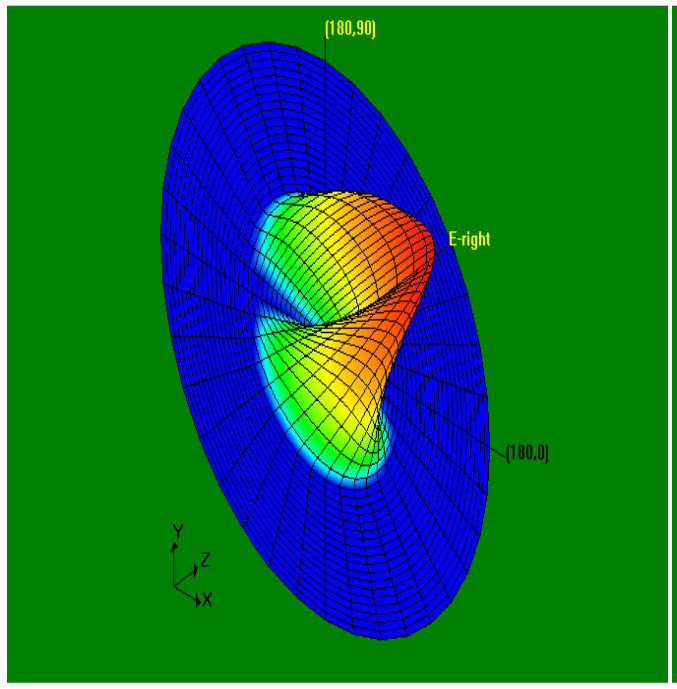

Figure 7: E-Plane Radiation Pattern (3D) for slotted antenna at $9.61 \mathrm{GHz}$

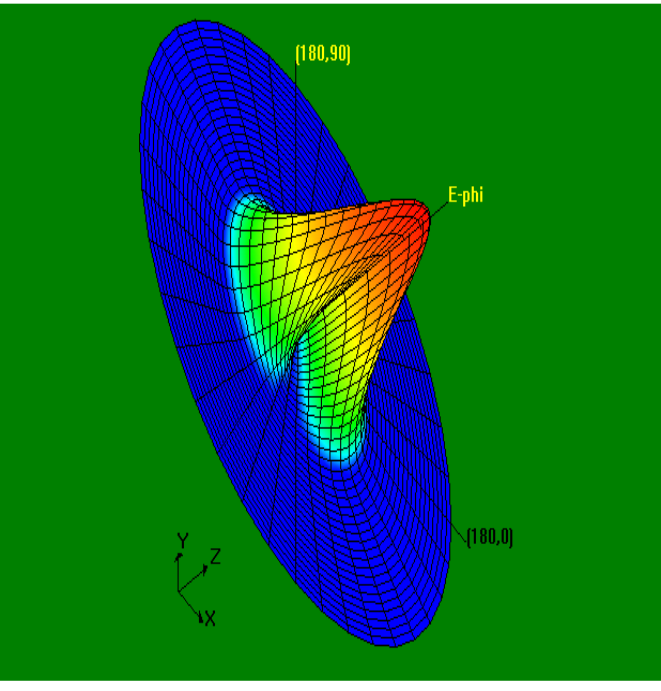

Figure 8: E-Plane Radiation Pattern (3D) for slotted antenna at $9.61 \mathrm{GHz}$

The simulated E plane radiation pattern of slotted antenna for $13.57 \mathrm{GHz}$ is shown in figure 9 . The simulated $\mathrm{H}$ plane radiation pattern of slotted antenna for $13.57 \mathrm{GHz}$ is shown in figure 10 . 


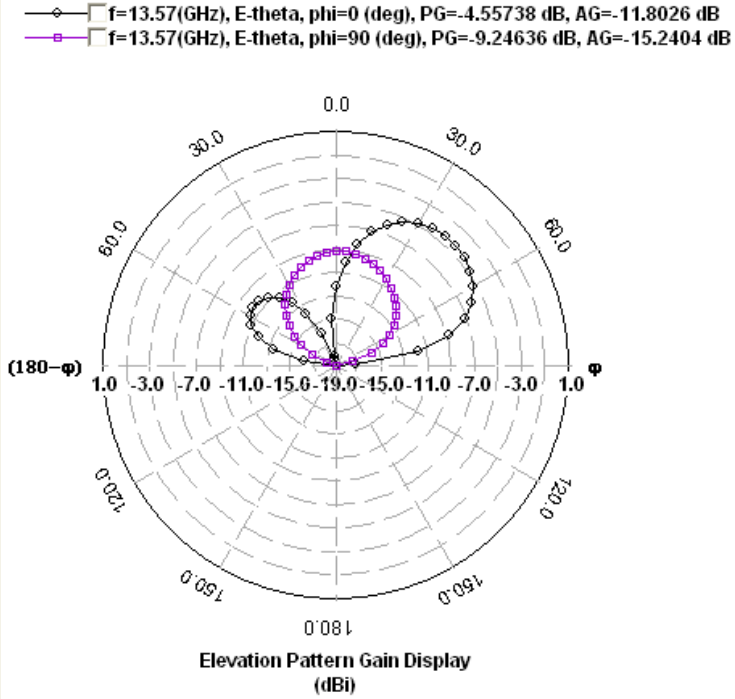

Figure9: E-Plane Radiation Pattern for slotted antenna at $13.57 \mathrm{GHz}$

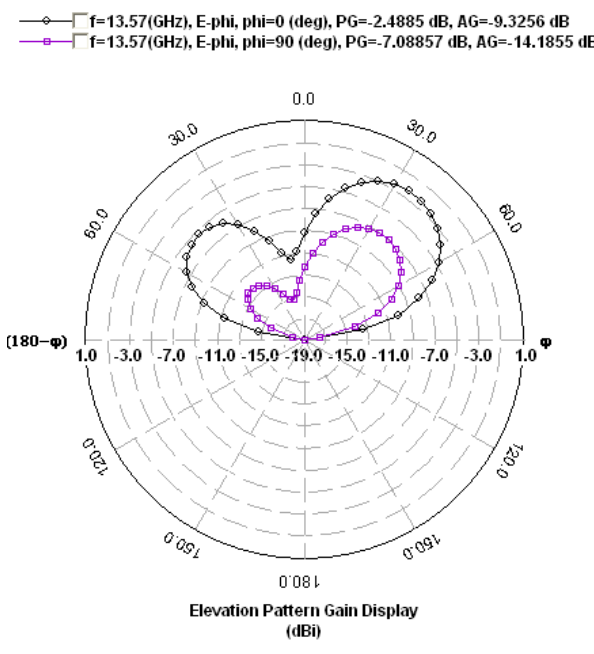

Figure 10: H-Plane Radiation Pattern for slotted antenna at $13.57 \mathrm{GHz}$

The simulated E -plane \& H-plane radiation pattern (3D) of simulated antenna for $13.57 \mathrm{GHz}$ is shown in figure $11 \&$ figure 12 .

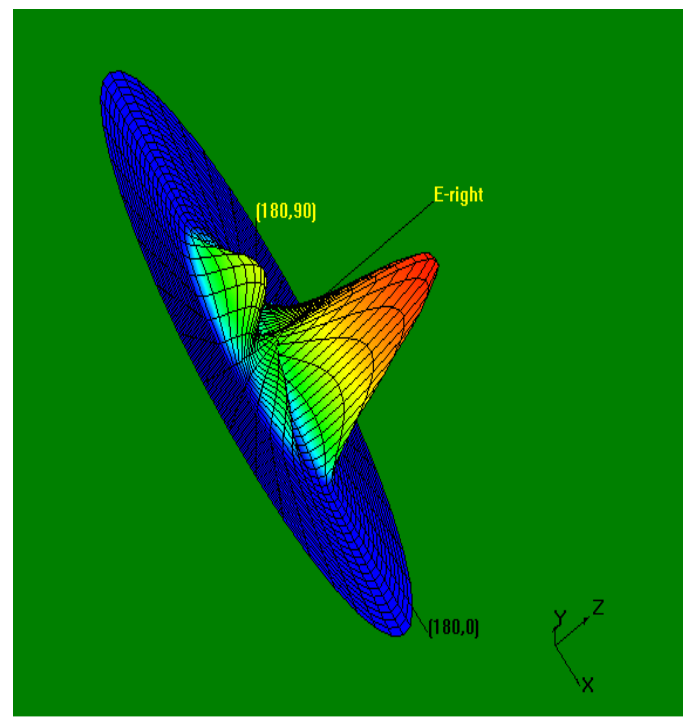

Figure11: E-Plane Radiation Pattern for slotted antenna at $13.57 \mathrm{GHz}$

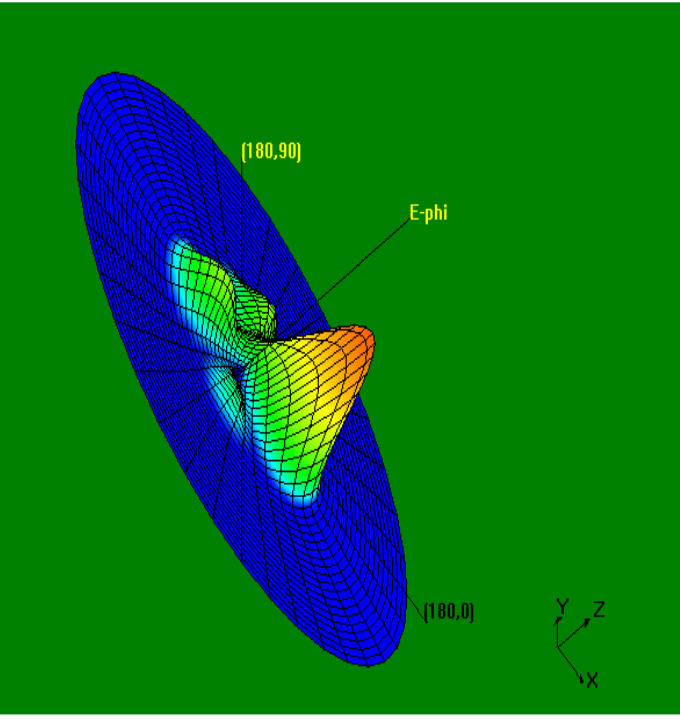

Figure 12: H-Plane Radiation Pattern for slotted antenna at $13.57 \mathrm{GHz}$

All the simulated results are summarized in the following Table1 and Table2. 
TABLE I: Simulated Results for Antenna 1 And 2 W.R.T Return Loss

\begin{tabular}{|c|c|c|c|}
\hline $\begin{array}{c}\text { ANTENNA } \\
\text { STRUCTURE }\end{array}$ & $\begin{array}{c}\text { RESONANT } \\
\text { FREQUENCY } \\
\text { (GHz) }\end{array}$ & $\begin{array}{c}\text { RETURN } \\
\text { LOSS } \\
(\mathbf{d B})\end{array}$ & $\begin{array}{c}\text { 10 DB } \\
\text { BANDWIDTH } \\
\text { (GHz) }\end{array}$ \\
\hline Conventional & $\mathrm{f}_{1}=13.39$ & -7.00 & NA \\
\hline \multirow{2}{*}{ Slotted } & $\mathrm{f}_{1}=9.61$ & -34 & 0.718 \\
\cline { 2 - 4 } & $\mathrm{f}_{2}=13.57$ & -31.2 & 1.4806 \\
\hline
\end{tabular}

TABLE II: Simulated Results for Antenna 1 And 2 W.R.T Radiation Pattern

\begin{tabular}{|c|c|c|c|}
\hline $\begin{array}{c}\text { ANTENNA } \\
\text { STRUCTURE }\end{array}$ & $\begin{array}{c}\text { RESONANT } \\
\text { FREUENCY } \\
(\mathbf{G H z})\end{array}$ & $\begin{array}{c}\text { 3DB } \\
\text { BEAMWIDTH } \\
\text { ( })\end{array}$ & $\begin{array}{c}\text { ABSOLUTE } \\
\text { GAIN } \\
(\boldsymbol{d B i})\end{array}$ \\
\hline \multirow{2}{*}{ Conventional } & $\mathrm{f}_{1}=13.39$ & $\mathrm{NA}$ & NA \\
\hline \multirow{2}{*}{ Slotted } & $\mathrm{f}_{1}=9.61$ & 162.075 & 3.35714 \\
\cline { 2 - 4 } & $\mathrm{f}_{2}=13.57$ & 53.445 & -0.428571 \\
\hline
\end{tabular}

\section{CONCLuSion}

This paper focused on the simulated design on differentially-driven microstrip antennas. Simulation studies of a single layer monopole hexagonal microstrip patch antenna have been carried out using Method of Moment based software IE3D. Introducing slots at the edge of the patch size reduction of about $54.55 \%$ has been achieved. The $3 \mathrm{~dB}$ beam-width of the radiation patterns are $162.075^{\circ}$ (for $\mathrm{f}_{1}$ ), $53.445^{\circ}$ (for $\mathrm{f}_{2}$ ) which is sufficiently broad beam for the applications for which it is intended.

The resonant frequency of slotted antenna, presented in the paper, designed for a particular location of feed point $(2.85 \mathrm{~mm}, 2.7 \mathrm{~mm})$ considering the centre as the origin. Alteration of the location of the feed point results in narrower $10 \mathrm{~dB}$ bandwidth and less sharp resonances.

\section{ACKNOWLEDGEMENT}

M. Mukherjee wishes to acknowledge Defense Research and Development Organization (DRDO, Ministry of Defense), Govt. of India for their financial assistance.

\section{REFERENCES}

[1] I.Sarkar, P.P.Sarkar, S.K.Chowdhury "A New Compact Printed Antenna for Mobile Communication”, 2009 Loughborough Antennas\& Propagation Conference, 16-17 November 2009, pp 109-112.

[2] S. Chatterjee, U. Chakraborty, I.Sarkar, S. K. Chowdhury, and P.P.Sarkar, "A Compact Microstrip Antenna for Mobile Communication”, IEEE annual conference. Paper ID: 510

[3] J.-W. Wu, H.-M. Hsiao, J.-H. Lu and S.-H. Chang, "Dual broadband design of rectangular slot antenna for 2.4 and $5 \mathrm{GHz}$ wireless communication", IEE Electron. Lett. Vol. 40 No. 23, 11th November 2004.

[4] U. Chakraborty, S. Chatterjee, S. K. Chowdhury, and P. P. Sarkar, "A comact microstrip patch antenna for wireless communication," Progress In Electromagnetics Research C, Vol. 18, 211-220, 2011 http://www.jpier.org/pierc/pier.php?paper=10101205 
[5] Rohit K. Raj, Monoj Joseph, C.K. Anandan, K. Vasudevan, P. Mohanan, “ A New Compact Microstrip-Fed Dual-Band Coplaner Antenna for WLAN Applications”, IEEE Trans. Antennas Propag., Vol. 54, No. 12, December 2006, pp 3755-3762.

[6] Zhijun Zhang, Magdy F. Iskander, Jean-Christophe Langer, and Jim Mathews, "Dual-Band WLAN Dipole Antenna Using an Internal Matching Circuit", IEEE Trans. Antennas and Propag.,VOL. 53, NO. 5, May 2005, pp 1813-1818.

[7] J. -Y. Jan and L. -C. Tseng, " Small planar monopole Antenna with a shorted parasitic inverted-L wire for Wireless communications in the 2.4, 5.2 and $5.8 \mathrm{GHz}$. bands", IEEE Trans. Antennas and Propag., VOL. 52, NO. 7, July 2004, pp -1903-1905.

[8] Samiran Chatterjee, Joydeep Paul, Kalyanbrata Ghosh, P. P. Sarkar and S. K. Chowdhury "A Printed Patch Antenna for Mobile Communication", Convergence of Optics and Electronics conference, 2011, Paper ID: 15, pp 102-107

[9] C. A. Balanis, “Advanced Engineering Electromagnetics”, John Wiley \& Sons., New York, 1989.

[10] Bipa Datta, Arnab Das, Samiran Chatterjee, Bipadtaran Sinhamahapatra, Supriya Jana, Moumita Mukherjee, Santosh Kumar Chowdhury, "Design of Compact Patch Antenna for Multi-Band Microwave Communication”, National Conference on Sustainable Development through Innovative Research in Science and Technology (Extended Abstracts), Paper ID: 115, pp 155, 2012

[11] Arnab Das, Bipa Datta, Samiran Chatterjee, Bipadtaran Sinhamahapatra, Supriya Jana, Moumita Mukherjee, Santosh Kumar Chowdhury, "Multi-Band Microstrip Slotted Patch Antenna for Application in Microwave Communication," International Journal of Science and Advanced Technology, (ISSN 2221-8386), Vol. 2, Issue-9, 91-95, September 2012.

[12] Zeland Software Inc. IE3D: MoM-Based EM Simulator. Web: http://www.zeland.com/ 